\title{
“MEASURING BURNOUT LEVELS \& ITS RELATIONSHIP ON WORK LIFE BALANCE AMONG CORPORATE HOSPITAL DOCTORS"
}

\author{
ROMA CHAVAN ${ }^{1}$, D. SUDARSANA MURTHY ${ }^{2}$ \& T. NARAYAN REDDY ${ }^{3}$ \\ ${ }^{1}$ Research Scholar Department of Management Studies Jawaharlal Nehru Technological University, Anantapuramu,
} Andhra Pradesh, India

${ }^{2}$ Professor, SreeVidyanikethan Institute of Management-A.Rangampet, Tirupati, Andhra Pradesh, India ${ }^{3}$ Associate Professor, Additional Control of Examination, Jawaharlal Nehru Technological University,

Anantapuramu, Andhra Pradesh, India

Work Life Balance is an imperative characteristic of the place of work and is increasing in importance to retain a hale and hearty \& enthused work force. Doctors are working round the clock $24 * 7$ and 365 days \& committed to their services. During this process sometimes they may not get time to spare their important time for their family. Past reviews show that the hectic workload leading to burnout [bad WLB] and reduces work and family life satisfaction. Burnout has sweeping consequences for physicians, Patients and the system of health care. Doctors with burnout are reported to be at a greater danger of making bad choices; show antagonistic attitudes towards patients; make more medical mistakes, and have hard interactions with colleagues. The present study is to come up with the objectives of identifying burnout factors and their impact on work life balance among corporate hospital doctors. The researcher used the standard scale (MBI) “Burnout Self-Test Maslach Burnout Inventory", to know about scale reliability researcher applied reliability test and all scale items were got above $85 \%$ Cronbach alpha values. The sample size was drawn from Hyderabad corporate hospital doctor's i.e 515. Used factor analysis to find out the major influencing factors and further used correlation analysis to measure burnout levels \& its relationship on work life balance among corporate hospital doctors. The results were presented and discussed in the study based on the hypothesis results.

KEYWORDS: Burnout, Work Life Balance \& Corporate Hospital Doctors
\end{abstract}

Received: Mar 20, 2021; Accepted: Apr 10, 2021; Published: Aug 18, 2021; Paper Id.: IJHRMRDEC20215

\section{INTRODUCTION}

Healthcare professionals often conquer private requirements for their job, and these sacrifices can create challenging the maintenance of good work-life Balance (WLB). Healthcare delivery can be wealthy in significant interactions, logical inspiration, and private fulfillment. Nevertheless, time requirements, badly constructed schemes and awry incentives can be inexorable with detrimental effects, including problems in personal life, immune system dysfunction and short-lived life expectancy. There is increasing concern about the psychosocial features of modern health care employees as burnout and discontent with WLB continue to rise(Schwartz et al. 2019).

Many doctors expressed that they are experienced with high level of burnout and a set of symptoms that they felt they are losing interest towards the professional work (emotional exhaust), feelings of pessimism (depersonalization) and a low sense of personal achievement. Recent study findings indicate that burnout can erode professionalism, affect quality of care, boost the likelihood of medical errors, and encourage early retirement. 
Burnout also appears to have negative personal effects on doctors, including contributions to broken friendships, troubled alcohol use, and suicidal thinking(Shanafelt et al. 2012).

\section{REVIEW OF LITERATURE}

In a study conducted by (Sagalowsky et al. 2019) it was shown that burnout is common among pediatric inhabitants, and for pediatric residency programs, lowering burnout is a concern. Understanding the private conditions of inhabitants, including happiness with the relationship and perceived conflict between work and life, can recognize new burnout determinants.

In another major study, (Hayes et al. 2019) found that burnout, work-life balance, presenteism, job capacity (balance between job and private assets) and the willingness to practice in Ireland's trainee and consultant hospital doctors to evaluate levels of occupational stress.

A recent systematic literature review concluded that (Mushfiqur et al. 2018) The aim of the researchers is to explore the consequences for Nigerian women medical doctors of work-life-balance (WLB) problems. This research focuses on Nigeria, which is a challenge for women medical doctors due to its unique and diversity in socio-cultural, institutional \& professional realities compose the challenge of social sustainability and work life balance for female physicians.

Detailed examination conducted by (Khalid and Rathore 2018) on WLB and they found that the most of the studies have developed Work-Life Balance (WLB) backgrounds and results. Factors such as supervisor assistance, organizational support and work value for public hospital post-graduate trainees at the WLB.

The study by (Kumar 2016) offers probably the most comprehensive empirical analysis of burnout and the researcher found that throughout their job, doctors are subjected to elevated concentrations of stress is prone to burnout. Burnout and its consequences for physicians, Patients and the system of health care. Doctors with burnout are reported to be at a greater danger of making bad choices; show unreceptive approach towards patients; make more professional mistakes; and have hard interactions with colleagues.

\section{RESEARCH OBJECTIVES}

- To identify the factors influencing burnout levels on corporate hospital doctors

- To measure the various burnout levels on corporate hospital doctors

- To analyze the burnout levels and its relationship with work life balance on corporate hospital doctors 


\section{Conceptual Framework}

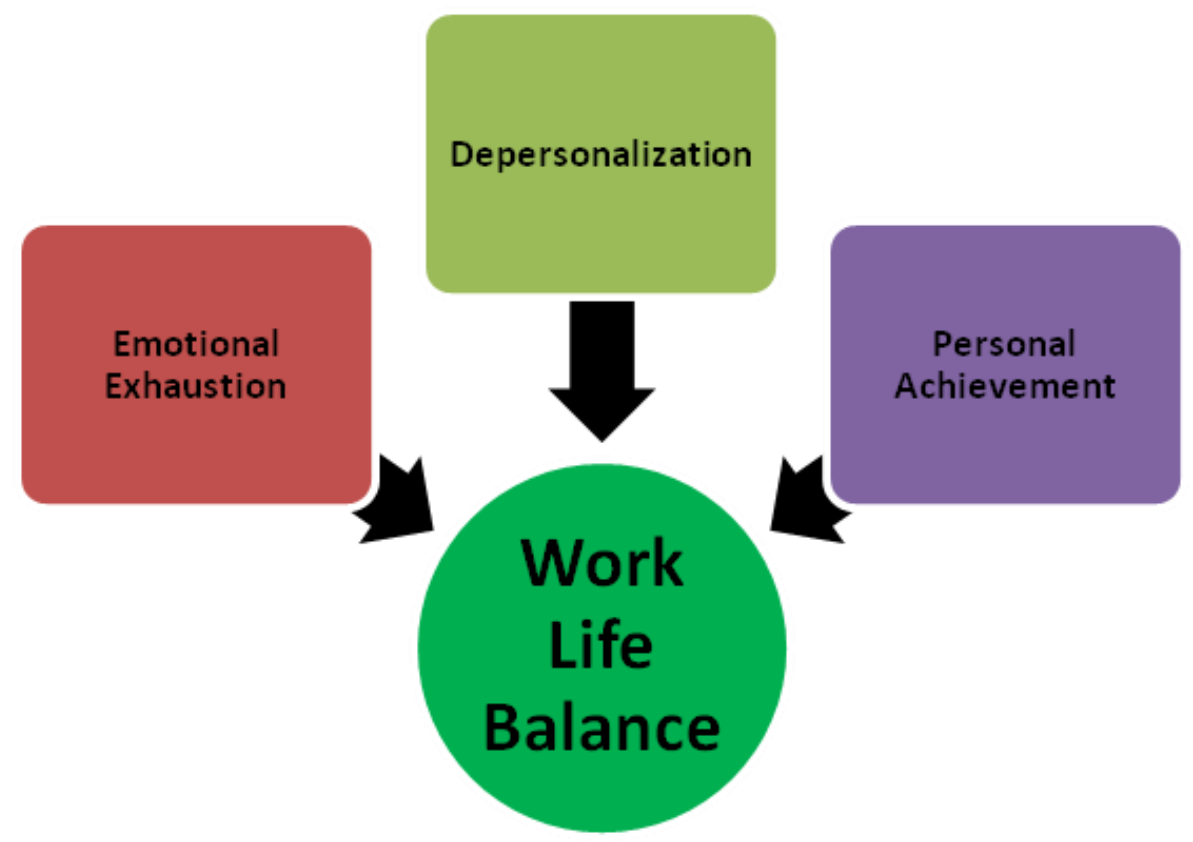

Figure 1

\section{RESEARCH METHODOLOGY}

Table: 1

\begin{tabular}{|l|l|}
\hline \multicolumn{1}{|c|}{ Methodology Elements } & \multicolumn{1}{c|}{ Methodology Description } \\
\hline Research Nature & Descriptive Study \\
\hline Location & Hyderabad, Telangana. \\
\hline Sample Size Determination & Glenn Sample size Table (1992) \\
\hline Sample Size & 515 Respondents \\
\hline Source of Data & Primary Sources \\
\hline Sample Selection Technique & Convenient Sample (Non - Probability) \\
\hline Data Collection Techniques & Structured Questionnaire through Google forms \\
\hline Measuring Scale & Likert 5-point rating scale \\
\hline Data Analysis Techniques & $\begin{array}{l}\text { Descriptive Statistics, Cronbach's Alph, EFA, Correlation } \\
\text { (SPSS-23.0v), }\end{array}$ \\
\hline
\end{tabular}

\section{Hypothesis}

- $\mathrm{H}_{1}$ : Emotional Exhaustion has significant positive relationship with work life balance.

- $\mathrm{H}_{2}$ : Depersonalization has significant positive relationship with work life balance.

- $\mathrm{H}_{3}$ : Personal achievement has significant positive relationship with work life balance. 


\section{RESULTS AND DISCUSSIONS}

Table 2: Burnout - Emotional Exhaustion

\begin{tabular}{|l|c|c|c|c|c|c|c|}
\hline & BEE1 & BEE2 & BEE3 & BEE4 & BEE5 & BEE6 & BEE7 \\
\hline Once a month & 3 & 2 & 4 & 2 & 2 & 2 & 9 \\
\hline A few times per month & 21 & 17 & 29 & 22 & 34 & 19 & 102 \\
\hline Once a week & 86 & 106 & 116 & 123 & 91 & 128 & 193 \\
\hline A few times per week & 330 & 305 & 305 & 317 & 277 & 295 & 177 \\
\hline Every day & 75 & 85 & 61 & 51 & 111 & 71 & 34 \\
\hline Total & $\mathbf{5 1 5}$ & $\mathbf{5 1 5}$ & $\mathbf{5 1 5}$ & $\mathbf{5 1 5}$ & $\mathbf{5 1 5}$ & $\mathbf{5 1 5}$ & $\mathbf{5 1 5}$ \\
\hline SUM & $\mathbf{1 9 9 8}$ & $\mathbf{1 9 9 9}$ & $\mathbf{1 9 3 5}$ & $\mathbf{1 9 3 8}$ & $\mathbf{2 0 0 6}$ & $\mathbf{1 9 5 9}$ & $\mathbf{1 6 7 0}$ \\
\hline Mean & $\mathbf{3 . 8 8}$ & $\mathbf{3 . 8 8}$ & $\mathbf{3 . 7 6}$ & $\mathbf{3 . 7 6}$ & $\mathbf{3 . 9}$ & $\mathbf{3 . 8}$ & $\mathbf{3 . 2 4}$ \\
\hline Std. Deviation & $\mathbf{0 . 7 1 7}$ & $\mathbf{0 . 7 2 4}$ & $\mathbf{0 . 7 6 2}$ & $\mathbf{0 . 6 9 9}$ & $\mathbf{0 . 8 2 6}$ & $\mathbf{0 . 7 2 9}$ & $\mathbf{0 . 9 0 5}$ \\
\hline Cronbach's Alpha & \multicolumn{7}{|c|}{} \\
\hline BE88
\end{tabular}

BEE1: "I Feel emotionally drained by my work", BEE2: "Working with people all day long requires a great deal of effort", BEE3: "I feel like my work is breaking me down", BEE4: "I feel frustrated by my work", BEE5: "I feel I work too hard at my job", BEE6: "It stresses me too much to work in direct contact with people", BEE7: "I feel like I'm at the end of my rope"'

From the above table 2 it has been observed that the emotional exhaustion was measured based on 7 items and its frequency has been mentioned based on item wise. BEE5 has got with highest mean value i.e 3.9 and followed by BEE1\&BEE2 got 3.88 and remaining BEE3 \& BEE4 with mean value is 3.76 and least value scored by BEE7 with 3.24 . Cronbach's Alpha value of emotional exhaustion variable is .888 which indicates there is a great internal consistency among items to rely on the scale.

Table 3: Burnout - Depersonalization

\begin{tabular}{|c|c|c|c|c|c|c|c|}
\hline & BDP1 & BDP2 & BDP3 & BDP4 & BDP5 & BDP6 & BDP7 \\
\hline Once a month & 10 & 10 & 12 & 10 & 13 & 7 & 8 \\
\hline A few times per month & 72 & 71 & 55 & 39 & 88 & 51 & 44 \\
\hline Once a week & 161 & 148 & 152 & 97 & 162 & 125 & 110 \\
\hline A few times per week & 220 & 232 & 244 & 314 & 204 & 273 & 283 \\
\hline Every day & 52 & 54 & 52 & 55 & 48 & 59 & 70 \\
\hline Total & 515 & 515 & 515 & 515 & 515 & 515 & 515 \\
\hline SUM & 1777 & 1794 & 1814 & 1910 & 1731 & 1871 & 1908 \\
\hline Mean & 3.45 & 3.48 & 3.52 & 3.71 & 3.36 & 3.63 & 3.7 \\
\hline Std. Deviation & 0.92 & 0.924 & 0.898 & $\mathbf{0 . 8 3}$ & 0.955 & 0.862 & 0.863 \\
\hline Cronbach's Alpha & \multicolumn{7}{|c|}{.939} \\
\hline \multicolumn{8}{|c|}{$\begin{array}{l}\text { BDP1: "I feel I look after certain patients/clients impersonally, as if they are objects", BDP2: "I feel tired when I get } \\
\text { up in the morning and have to face another day at work", BDP3: "I have the impression that my patients/clients make } \\
\text { me responsible for some of their problems", BDP4: "I am at the end of my patience at the end of my work day", } \\
\text { BDP5: "I really don't care about what happens to some of my patients/clients", BDP6: "I have become more } \\
\text { insensitive to people since I've been working", BDP7: "I'm afraid that this job is making me uncaring". }\end{array}$} \\
\hline
\end{tabular}

Table 3 compares the summary statistics for depersonalization variable item statistics Cronbach's alpha value is .939 which indicates there is an excellent internal consistency among items in the variable. Item BDP4 has got highest mean value i.e 3.71 and lowest is 3.36 i.e item BDP5. Rest followed by BDP7, BDP5, BDP3, BDP2 \& BDP1 with a mean values $3.7,3.63,3.52,3.48, \& 3.45$ 
Table 4: Burnout - Personal Achievement

\begin{tabular}{|c|c|c|c|c|c|c|c|c|}
\hline & BPA1 & BPA2 & BPA3 & BPA4 & BPA5 & BPA6 & BPA7 & $\overline{\text { BPA8 }}$ \\
\hline Once a month & 0 & 1 & 1 & 1 & 1 & 3 & 0 & 1 \\
\hline A few times per month & 21 & 18 & 14 & 13 & 9 & 12 & 6 & 18 \\
\hline Once a week & 65 & 76 & 86 & 87 & 81 & 58 & 84 & 76 \\
\hline A few times per week & 306 & 319 & 304 & 312 & 299 & 319 & 284 & 320 \\
\hline Every day & 123 & 101 & 110 & 102 & 125 & 123 & 141 & 100 \\
\hline Total & 515 & 515 & 515 & 515 & 515 & 515 & 515 & 515 \\
\hline SUM & 2076 & 2046 & 2053 & 2046 & 2083 & 2092 & 2105 & 2045 \\
\hline Mean & 4.03 & 3.97 & 3.99 & 3.97 & 4.04 & 4.06 & 4.09 & 3.97 \\
\hline Std. Deviation & 0.727 & 0.708 & 0.712 & 0.697 & 0.697 & 0.703 & 0.69 & 0.707 \\
\hline Cronbach's Alpha & \multicolumn{8}{|c|}{.953} \\
\hline \multicolumn{9}{|c|}{$\begin{array}{l}\text { BPA1: "I accomplish many worthwhile things in this job", BPA2: "I feel full of energy", BPA3: "I am easily able to } \\
\text { understand what my patients/clients feel", BPA4: "I look after my patients'/clients' problems very effectively", } \\
\text { BPA5: "In my work, I handle emotional problems very calmly", BPA6: "Through my work, I feel that I have a } \\
\text { positive influence on people", BPA7: "I am easily able to create a relaxed atmosphere with my patients/clients", } \\
\text { BPA8: "I feel refreshed when I have been close to my patients/clients at work". }\end{array}$} \\
\hline
\end{tabular}

As shown, table 4 provides the results obtained from the preliminary analysis of variable called personal achievement Cronbach's alpha value is .953 and it indicates that the strong internal consistency between items. Highest Mean value 4.09 is bagged by BPA7 and least mean value with item BPA2, BPA4 \& BPA8.

Table 5: Work Life Balance

\begin{tabular}{|c|c|c|c|c|}
\hline & WLB1 & WLB2 & WLB3 & WLB4 \\
\hline Strongly Disagree & 38 & 27 & 31 & 33 \\
\hline Disagree & 99 & 63 & 58 & 92 \\
\hline Neither Agree nor Disagree & 142 & 127 & 114 & 132 \\
\hline Agree & 205 & 256 & 252 & 207 \\
\hline Strongly Agree & 31 & 42 & 60 & 51 \\
\hline Total & 515 & 515 & 515 & 515 \\
\hline Mean & 3.18 & 3.43 & 3.49 & 3.29 \\
\hline Std. Deviation & 1.047 & 0.985 & 1.035 & 1.072 \\
\hline Cronbach's Alpha & \multicolumn{4}{|c|}{.893} \\
\hline \multicolumn{5}{|c|}{$\begin{array}{l}\text { WLB1: "I am satisfied with my work life balance, enjoying both roles", WLB2: "Nowadays, I seem to enjoy every } \\
\text { part of my life equally well", WLB3: "I manage to balance the demands of my work and personal life well", } \\
\text { WLB4: "Work schedule leaves me enough time for my personal and/ or family life" }\end{array}$} \\
\hline
\end{tabular}

As can be seen from the above table5 the experiential data on variable called work life balance and its Cronbach's alpha value is .893 , which states that the items internal consistency is good. Furthermore, it has been shown that the item WLB3 got highest mean value with 3.49 and remaining followed by WLB2 with mean 3.43, WLB4 with mean value 3.29 and WLB1 with lowest mean value 3.18.

$\mathrm{H}_{1}$ : Emotional Exhaustion has significant positive relationship with work life balance. 
Table 6: (Descriptive Statistics)

\begin{tabular}{|c|c|c|c|c|c|c|}
\hline & & \multirow{3}{*}{ (Statistic) } & \multicolumn{4}{|c|}{$\left(\right.$ Bootstrap $\left.^{\mathrm{a}}\right)$} \\
\hline & & & \multirow[t]{2}{*}{ (Bias) } & \multirow{2}{*}{$\begin{array}{l}\text { (Std. } \\
\text { Error) }\end{array}$} & \multicolumn{2}{|c|}{$\begin{array}{c}\text { (95\% Confidence } \\
\text { Interval) }\end{array}$} \\
\hline & & & & & (Lower) & (Upper) \\
\hline \multirow{3}{*}{ Emotional Exhaustion } & (Mean) & 3.7462 & -.0003 & .0258 & 3.6951 & 3.7975 \\
\hline & Std. Deviation & .59449 & .00003 & .02598 & .54466 & .64828 \\
\hline & $\mathrm{N}$ & 515 & 0 & 0 & 515 & 515 \\
\hline \multirow{3}{*}{ Work Life Balance } & Mean & 3.3485 & .0010 & .0384 & 3.2728 & 3.4248 \\
\hline & Std. Deviation & .90105 & -.00105 & .02752 & .84631 & .95938 \\
\hline & $\mathrm{N}$ & 515 & 0 & 0 & 515 & 515 \\
\hline
\end{tabular}

a. Based on 1000 bootstrap samples From the above table 6 it reveals that the bootstrapping is done based on $95 \%$ confidence interval where emotional exhaustion variable got 3.7975 upper level and 3.6951 with lower level but whereas work life balance variable got 3.4248 with upper level and 3.2728 with lower level.

Table 7: Correlations

\begin{tabular}{|c|c|c|c|c|c|}
\hline & & & & $\begin{array}{l}\text { Emotional } \\
\text { Exhaustion }\end{array}$ & $\begin{array}{c}\text { Work Life } \\
\text { Balance }\end{array}$ \\
\hline \multirow{9}{*}{$\begin{array}{l}\text { Emotional } \\
\text { Exhaustion }\end{array}$} & \multicolumn{3}{|c|}{ (Pearson Correlation) } & 1 & .016 \\
\hline & \multicolumn{3}{|l|}{ Sig. (2-tailed) } & & .719 \\
\hline & \multicolumn{3}{|c|}{ (Sum of Squares and Cross-products) } & 181.660 & 4.381 \\
\hline & \multicolumn{3}{|l|}{ (Covariance) } & .353 & .009 \\
\hline & \multicolumn{3}{|l|}{$\mathrm{N}$} & 515 & 515 \\
\hline & \multirow{4}{*}{$\left(\right.$ Bootstrap $\left.^{\mathrm{c}}\right)$} & \multicolumn{2}{|l|}{$\begin{array}{l}\text { (Bias) } \\
\text { (Std Frror) }\end{array}$} & 0 & .000 \\
\hline & & \multicolumn{2}{|l|}{ (Std. Error) } & 0 & .045 \\
\hline & & \multirow{2}{*}{$\begin{array}{l}\text { (95\% Confidence } \\
\text { Interval) }\end{array}$} & (Lower) & 1 & -.068 \\
\hline & & & (Upper) & 1 & .102 \\
\hline
\end{tabular}

Table 7 shows the inter correlations among the 7 measures each (Emotional exhaustion and Work life balance) that the correlation between emotional exhaustion and work life balance is $r=.016$ and significant value is .719 which is greater than p-value $0.05(\alpha>5 \%)$, hence reject alternative hypothesis and accept null hypothesis i.e Emotional Exhaustion does not have significant positive relationship with work life balance. Based on the significant value we may conclude that there is a weak relationship between emotional exhaustion and work life balance on corporate hospital doctors.

$\mathrm{H}_{2}$ : Depersonalization has significant positive relationship with work life balance.

Table 8: (Descriptive Statistics)

\begin{tabular}{|c|c|c|c|c|c|c|}
\hline & & \multirow{3}{*}{ (Statistic) } & \multicolumn{4}{|c|}{ Bootstrap $^{a}$} \\
\hline & & & \multirow{2}{*}{ (Bias) } & \multirow{2}{*}{ (Std. Error) } & \multicolumn{2}{|c|}{ 95\% Confidence Interval } \\
\hline & & & & & (Lower) & (Upper) \\
\hline \multirow{3}{*}{ Depersonalization } & (Mean) & 3.5520 & .0004 & .0336 & 3.4866 & 3.6191 \\
\hline & Std. Deviation & .76482 & -.00125 & .02727 & .70769 & .81472 \\
\hline & $\mathrm{N}$ & 515 & 0 & 0 & 515 & 515 \\
\hline \multirow{3}{*}{ Work Life Balance } & Mean & 3.3485 & .0014 & .0388 & 3.2782 & 3.4252 \\
\hline & Std. Deviation & .90105 & -.00035 & .02647 & .84942 & .95430 \\
\hline & $\mathrm{N}$ & 515 & 0 & 0 & 515 & 515 \\
\hline
\end{tabular}

From the above table 8, it reveals that the bootstrapping is done based on $95 \%$ confidence interval where depersonalization variable got 3.6191 upper level and 3.4866 with lower level but whereas work life balance variable got 
3.4252 with upper level and 3.2782 with lower level.

Table 9:Correlations

\begin{tabular}{|c|c|c|c|c|c|}
\hline & & & & Depersonalization & Work Life Balance \\
\hline \multirow{9}{*}{ Depersonalization } & \multicolumn{3}{|c|}{ (Pearson Correlation) } & 1 & .022 \\
\hline & \multicolumn{3}{|c|}{ Sig. (2-tailed) } & & .619 \\
\hline & \multicolumn{3}{|c|}{ (Sum of Squares and Cross-products) } & 300.663 & 7.771 \\
\hline & \multicolumn{3}{|c|}{ (Covariance) } & .585 & .015 \\
\hline & \multicolumn{3}{|l|}{$\mathrm{N}$} & 515 & 515 \\
\hline & \multirow{4}{*}{$\left(\right.$ Bootstrap $\left.^{c}\right)$} & \multicolumn{2}{|l|}{ (Bias) } & 0 & .000 \\
\hline & & \multicolumn{2}{|l|}{ (Std. Error) } & 0 & .041 \\
\hline & & \multirow{2}{*}{ (95\% Confidence Interval) } & (Lower) & 1 & -.065 \\
\hline & & & (Upper) & 1 & .100 \\
\hline
\end{tabular}

\section{c. Based on 1000 bootstrap samples}

Table 9 shows that the inter correlations among the 7 measures each (Depersonalization and Work life balance) that the correlation between depersonalization and work life balance is $r=.022$ and significant value is .619 which is greater than p-value $0.05(\alpha>5 \%)$, hence accept null hypothesis i.e Depersonalization does not have significant positive relationship with work life balance. Based on the significant value we may conclude that there is a weak relationship between depersonalization and work life balance on corporate hospital doctors.

$\mathrm{H}_{3}$ : Personal achievement has significant positive relationship with work life balance.

Table 10: (Descriptive Statistics)

\begin{tabular}{|c|c|c|c|c|c|c|}
\hline & & \multirow{3}{*}{ (Statistic) } & \multicolumn{4}{|c|}{ (Bootstrap $^{\text {a) }}$} \\
\hline & & & \multirow[t]{2}{*}{ (Bias) } & \multirow{2}{*}{$\begin{array}{c}\text { (Std. } \\
\text { Error) }\end{array}$} & \multicolumn{2}{|c|}{$\begin{array}{l}\text { 95\% Confidence } \\
\text { Interval }\end{array}$} \\
\hline & & & & & (Lower) & (Upper) \\
\hline \multirow{3}{*}{ Personal Achievement } & (Mean) & 4.0160 & -.0010 & .0264 & 3.9627 & 4.0658 \\
\hline & Std. Deviation & .61186 & -.00111 & .02333 & .56298 & .65763 \\
\hline & $\mathrm{N}$ & 515 & 0 & 0 & 515 & 515 \\
\hline \multirow{3}{*}{ Work Life Balance } & Mean & 3.3485 & -.0008 & .0399 & 3.2680 & 3.4257 \\
\hline & Std. Deviation & .90105 & -.00058 & .02723 & .84471 & .95406 \\
\hline & $\mathrm{N}$ & 515 & 0 & 0 & 515 & 515 \\
\hline
\end{tabular}

a. Based on 1000 bootstrap samples

From the above table 10 it reveals that the bootstrapping is done based on $95 \%$ confidence interval where personal achievement variable got 4.0658 upper level and 3.9627 with lower level but whereas work life balance variable got 3.4257 with upper level and 3.2680 with lower level.

Table 11: Correlations

\begin{tabular}{|c|c|c|c|c|c|}
\hline & & & & $\begin{array}{c}\text { Personal } \\
\text { Achievement }\end{array}$ & $\begin{array}{c}\text { Work Life } \\
\text { Balance }\end{array}$ \\
\hline \multirow{9}{*}{$\begin{array}{l}\text { Personal } \\
\text { Achievement }\end{array}$} & \multicolumn{3}{|c|}{ (Pearson Correlation) } & 1 & .813 \\
\hline & \multicolumn{3}{|c|}{ Sig. (2-tailed) } & & .000 \\
\hline & \multicolumn{3}{|c|}{ (Sum of Squares and Cross-products) } & 192.430 & 3.750 \\
\hline & \multicolumn{3}{|l|}{ (Covariance) } & .374 & .007 \\
\hline & \multicolumn{3}{|l|}{$\mathrm{N}$} & 515 & 515 \\
\hline & \multirow{4}{*}{$\left(\right.$ Bootstrap $\left.^{c}\right)$} & \multicolumn{2}{|l|}{ (Bias) } & 0 & .000 \\
\hline & & \multicolumn{2}{|l|}{ (Std. Error) } & 0 & .041 \\
\hline & & \multirow{2}{*}{$\begin{array}{l}\text { (95\% Confidence } \\
\text { Interval) }\end{array}$} & (Lower) & 1 & -.070 \\
\hline & & & (Upper) & 1 & .095 \\
\hline
\end{tabular}


Table 11 shows that the inter correlations among the $7 \& 8$ measures each (Personal achievement and Work life balance) that the correlation between personal achievement and work life balance is $r=.813$ and significant value is .000 which is less than p-value $0.05(\alpha<5 \%)$, hence reject null hypothesis and accept alternative hypothesis i.e., Personal achievement has significant positive relationship with work life balance. Based on the significant value we may conclude that there is a strong and positive relationship between personal achievement and work life balance on corporate hospital doctors.

\section{CONCLUSIONS}

The doctor profession is a notable and noble profession in the world. Doctors will work round the clock because every time they were busy with operations, consulting and treating patients. During the process of treating the patients and spending in critical care unit's hours together, they may be emotionally exhausted which may cause stress because they could not spare enough time with their family members. Due to this, they may develop serious burnout issues and it may cause to imbalance of work and family life. The researcher mainly focused on burnout levels based on standard scale "Burnout SelfTest Maslach Burnout Inventory” (MBI). Based on the standard MBI scale three variables i.e emotional exhaustion, depersonalization \& personal achievement was measured with work life balance variable and found that most of the doctors felt that they were exposed to burnout levels and because of that they couldn't able to manage their family and work life.

\section{FUTURE RESEARCH}

- The present study was focused on Burnout levels based on standard scale. Future researchers may focus on other variables which may cause burnout i.e work demands, family demands and job autonomy.

- The present study was concentrated on burnout levels of corporate hospital doctors and their work life balance. Researchers may focus on demographical variables and its impact on work life balance among corporate hospital doctors.

- Researchers did not concentrate on work life balance and work life satisfaction by using burnout levels. There is a lot of future scope, to do extensive research on the present issue with respect to work life satisfaction.

- The present research study was focused on corporate hospital doctor's only So further scope is there to do comparative research on government and private doctors and their stress levels based on burnout issues.

- Future research also can be focus on using other personality trait variables which may cause stress and high burnout levels and their impact on work life balance especially on doctors.

\section{REFERENCES}

1. Shanafelt, Tait D. et al. 2012. "Burnout and Satisfaction with Work-Life Balance among US Physicians Relative to the General US Population." Archives of Internal Medicine 172(18): 1377-85.

2. Sagalowsky, Selin Tuysuzoglu et al. 2019. "Intimate Partner Relationships, Work-Life Factors, and Their Associations With Burnout Among Partnered Pediatric Residents." Academic Pediatrics 19(3): 263-68. https://doi.org/10.1016/j.acap.2018.09.005.

3. Hayes, Blánaid et al. 2019. "Doctors Don't Do-Little: A National Cross-Sectional Study of Workplace Well-Being of Hospital Doctors in Ireland." BMJ Open 9(3): 13-15. 
4. Schwartz, Stephanie P. et al. 2019. “Work-Life Balance Behaviours Cluster in Work Settings and Relate to Burnout and Safety Culture: A Cross-Sectional Survey Analysis.” BMJ Quality and Safety 28(2): 142-50.

5. Mushfiqur, Rahman et al. 2018. "The Impacts of Work-Life-Balance (WLB) Challenges on Social Sustainability: The Experience of Nigerian Female Medical Doctors. ” Employee Relations 40(5): 868-88.

6. Khalid, Afaf, and Kashif Rathore. 2018. "Mediating Effect of Work-Life Balance on Work Motivation of Post-Graduate Trainee Doctors in Public Sector Hospitals: Evidence From Pakistan.” Pakistan Economic and Social Review 56(1): 93-119.

7. Kumar, Shailesh. 2016. “Burnout and Doctors: Prevalence, Prevention and Intervention. ” Healthcare 4(3): 37.

8. Singh, Vijay Pratap, Enid Masih, and Manish Roy Tirkey. "Conceptualizing the Role of Worklife Balance Policy in Creating an Inclusive Workplace." International Journal of Human Resource Management and Research (IJHRMR) 4: 19-24.

9. Sharma, Rajiv Vyas\& RB. "A Study on Quality of Work Life Among Employees of Selected it Company in Hyderabad." International Journal of Business Management \& Research (IJBMR) 6.6: 25-34.

10. Venkatesh, S., and S. Arun Kumar. "A Comparative Study on Quality of Work Life In it, Banking and Psu Sectors in Tamil Nadu." International Journal of Business and General Management (IJBGM) 5: 1-10.

11. Battu, Nagaraju, and Shriram Darbha. "Holistic Employee Engagement for Achieving Peak Performance and Overall Satisfaction." International Journal of Business and General Management (IJBGM) 6.5: 23-32. 
